\title{
Coronavirus Disease 2019 and Re-infection with Different Symptoms: A case report
}

Hiva Alipanah $^{1}$, Ali Ghanbari Asad ${ }^{1}$, Yaser Mansoori ${ }^{1}$, Jalal Karimi ${ }^{1}$, Atefeh Taheri ${ }^{1}$, and Zahra Pourmontaseri ${ }^{1}$

${ }^{1}$ Affiliation not available

October 15, 2020

\begin{abstract}
Novel coronavirus disease (COVID-19) become one of the most important global health issues. With increasing the number of COVID-19 patients, the possibility of occurring re-infection in recovered patients is arising. There is still not proven that the recuperated COVID-19 patients are immunized against the SARS-CoV-2. Herein, we reported a case of COVID-19 who was previously infected with the gastrointestinal form of the disease. The patient was infected again after 97 days of the initial GI symptoms of the disease or 82 days of the post negative test. RT-PCR was also positive in the virus detection. This is the first report of COVID-19 patient with the longest period of time of re-infection which has been reported yet.
\end{abstract}

\section{Hosted file}

main document.pdf available at https://authorea.com/users/367338/articles/486947-coronavirusdisease-2019-and-re-infection-with-different-symptoms-a-case-report 

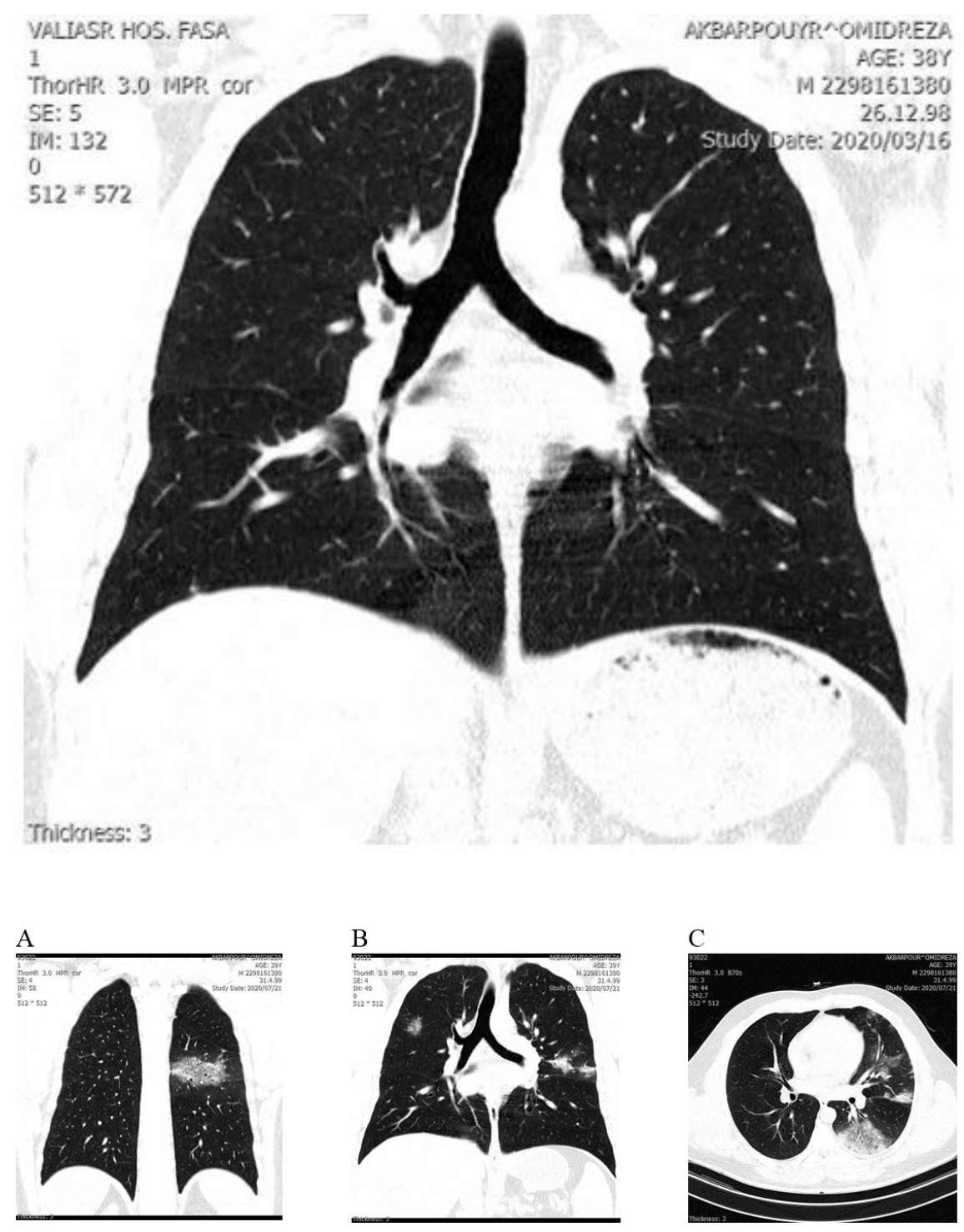